\title{
Perubahan Kapasitas Daya Dukung Pondasi Dangkal Dan Nilai PENURUNAN TANAH Pada TANAH Gambut YANG DISTABILISASI DENGAN KAPUR DAN FLY ASH
}

\author{
Rusliansyah $^{1)}$, Muhammad Afief Ma'ruf ${ }^{2)}$ \\ 1) Program Studi Teknik Sipil, Fakultas Teknik, Universitas \\ Lambung Mangkurat \\ Jl. A. Yani Km 35,5 Banjarbaru, 70714 \\ Email: rusliansyah@ulm.ac.id \\ ${ }^{2)}$ Program Studi Teknik Sipil, Fakultas Teknik, Universitas \\ Lambung Mangkurat \\ Jl. A. Yani Km 35,5 Banjarbaru, 70714 \\ Email: afief.maruf@ulm.ac.id
}

\begin{abstract}
Peat soil is a type of soft soil with low bearing capacity and high compressibility. Many efforts have been made to improve it. These efforts focus on improving the physical and mechanical characteristics of peat to increase bearing capacity and reduce its subsidence. One is stabilization method, which is by inserting a stabilizing material into peat soil to improve its physical properties and mechanical properties. From previous studies on a laboratory scale by considering the effect of water from peat soil around the stabilized area obtained optimum levels of mixture of stabilizing material for peat soils by $10 \%$ from the wet weight of peat soil.

Things that have not been taken into account in that study are still untested to be applied in the calculation of bearing capacity of shallow foundations for future field use applications, where the influence of water content from peat soil around the stabilized area will also have an effect.

The research was carried out by imitating the large shallow foundation that is commonly used in the community surrounding the land using laboratory methods of mechanical properties to obtain the characteristics of peat soil before and after stabilization. This parameter is then used as input data in calculating the bearing capacity of shallow foundations and the value of land subsidence. The result is for the value of bearing capacity after being mixed with stabilization material there is an increase. For initial peat soil the bearing capacity is $58,371 \mathrm{kPa}$, while after being mixed with stabilization material the bearing capacity increases to $654,606 \mathrm{kPa}$. While at the time of the consolidation test there was a decrease in the value of $68,57 \%$. Where at the time after mixing with the stabilization material the value was $1,49 \mathrm{~mm}$ while the initial peat soil was $4,74 \mathrm{~mm}$.
\end{abstract}

Keywords: Bearing Capacity, Consolidation, Peat

\begin{abstract}
Abstrak
Tanah gambut adalah jenis tanah lunak dengan daya dukung yang rendah dan kemampumampatan yang tinggi. Berkaitan dengan rendahnya daya dukung serta kemampumampatan yang tinggi dari tanah gambut, maka usaha - usaha untuk memperbaikinya juga telah banyak dilakukan. Usaha - usaha tersebut berfokus pada perbaikan sifat fisik dan teknis gambut untuk meningkatkan daya dukung dan mengurangi kemampumampatannya. Salah satu metode perbaikan tanah gambut adalah metode stabilisasi, yaitu dengan cara memasukkan suatu bahan stabilisasi ke dalam tanah gambut untuk memperbaiki sifat fisik dan sifat teknisnya. Dari penelitian sebelumnya dalam skala laboratorium telah diperoleh prosentase bahan stabilisasi optimum 30\% kapur dan 70\% fly ash. Penelitian lanjutan dengan memperhatikan pengaruh air dari tanah gambut di sekitar luasan yang distabilisasi memperoleh kadar campuran bahan stabilisasi optimum untuk tanah gambut sebesar 10\% dari berat basah tanah gambut.

Hal yang belum perhitungkan pada penelitian tersebut yaitu masih belum dicoba untuk diaplikasikan pada perhitungan daya dukung pondasi dangkal untuk aplikasi pemakaian lahan di lapangan nantinya, dimana dimana pengaruh kadar air dari tanah gambut di sekitar luasan yang distabilisasi juga akan memberikan pengaruh.

Penelitian dilakukan dengan mengimitasi besar pondasi dangkal yang umum digunakan pada masyarakat sekitar lahan tersebut menggunakan metode pengujian sifat teknis yaitu dengan uji direct shear dan uji konsolidasi agar diperoleh nilai karakteristik tanah gambut sebelum dan sesudah distabilisasi. Parameter ini kemudian digunakan sebaga input data pada perhitungan kapasitas daya dukung pondasi dangkal dan nilai penurunan tanah. Hasilnya adalah untuk nilai daya dukung setelah dicampur dengan bahan stabilisasi terjadi peningkatan. Untuk tanah tanah gambut inisial daya dukungnya sebesar $58,371 \mathrm{kPa}$, sedangkan setelah dicampur dengan bahan stabilisasi daya dukungnya meningkat menjadi 654,606 $\mathrm{kPa}$. Sedangkan pada saat pengujian konsolidasi terjadi penurunan nilai kemampumampatannya sebesar $68,57 \%$. Dimana pada saat setelah dicampur dengan bahan stabilisasi nilai kemampumampatannya sebesar $1,49 \mathrm{~mm}$ sementara nilai kemampumampatan tanah gambut inisial sebesar $4,74 \mathrm{~mm}$.
\end{abstract}

Kata Kunci: Daya Dukung Tanah, Gambut, Konsolidasi

\section{PENDAHULUAN}

\section{Latar Belakang}

Tanah gambut yang ada di Indonesia memiliki luas sekitar 20,1 juta hektar (Sumaryono, 2008) atau sekitar 10,8\% luas daratan Indonesia. Pada awalnya lahan tanah gambut kurang mendapatperhatian untuk dimanfaatkan serta kurang menarik dari sisi ekonomis, namun seiring dengan meningkatnya kebutuhan lahan akibat pertambahan jumlah penduduk dan pembangunan membuat lahan gambut menjadi salah satu pilihan lahan 
pembangunan. Beberapa proyek pemerintah untuk pemanfaatan lahan gambut sudah banyak direalisasikan, salah satunya adalah pembangunan ruas jalan baru di propinsi Kalimantan Tengah yang dibangun di atas tanah gambut.

Tanah gambut adalah jenis tanah lunak dengan daya dukung yang rendah dan kemampumampatan yang tinggi. Tanah gambut memiliki tekstur terbuka dimana selain pori-pori makro, tekstur tanah gambut juga didominasi oleh pori-pori mikro yang berada di dalam serat-serat gambut. Dengan sistem pori ganda dan tingkat homogenitas yang tidak merata tersebut, serta berat isi tanah yang mendekati berat isi air, maka masalah pemampatan (compressibility) yang besar bisa mengakibatkan penurunan (settlement) yang besar juga. Selain itu karena tanah gambut ini sangat lembek pada umumnya mempunyai daya dukung (bearing capacity) yang rendah, bahkan menurut penelitian Jelisic, Leppanen (1993) bahwa daya dukung tanah gambut lebih rendah dari pada tanah soft clay sehingga bisa mengakibatkan kelongsoron/keruntuhan (bearing capacity failure); hal ini menjadi masalah utama bagi struktur yang akan dibangun di atasnya.

Berkaitan dengan rendahnya daya dukung serta kemampumampatan yang tinggi dari tanah gambut, maka usaha - usaha untuk memperbaikinya juga telah banyak dilakukan. Usaha - usaha tersebut berfokus pada perbaikan sifat fisik dan teknis gambut untuk meningkatkan daya dukung dan mengurangi kemampumampatannya.

Salah satu metode perbaikan tanah gambut adalah metode stabilisasi, yaitu dengan cara memasukkan suatu bahan stabilisasi ke dalam tanah gambut untuk memperbaiki sifat fisik dan sifat teknisnya. Metode ini relatif lebih ramah lingkungan dibandingkan metode disposal, preloading ataupun cerucuk dan sand column. Hal ini karena metode stabilisasi tidak memerlukan areal tambahan untuk membuang gambut, serta tidak mengganggu keseimbangan ekosistem hutan dan quary seperti yang terjadi pada metode preloading, cerucuk ataupun sand column.

Bahan stabilisasi yang umum digunakan adalah bahan semen serta kapur; untuk gambut, telah dikembangkan bahan stabilisasi kapur yang dikombinasikan dengan bahan pozzolan sebagai sumber silika yaitu abu sekam dan fly ash. Kombinasi ini diperlukan karena kapur tidak memiliki kandungan silica sebagai bahan pengikat dengan tanah gambut. Untuk mengatasi hal tersebut maka selain kapur diperlukan bahan lain untuk campuran bahan stabilisasi tanah gambut, yang dalam hal ini adalah bahan pozzolan yang mengandung silica. Dari penelitian sebelumnya dalam skala laboratorium telah diperoleh prosentase bahan stabilisasi optimum 30\% kapur dan 70\% fly ash (Mochtar, N.E., dkk 2009). Penelitian lanjutan dengan memperhatikan pengaruh air dari tanah gambut di sekitar luasan yang distabilisasi memperoleh kadar campuran bahan stabilisasi optimum untuk tanah gambut sebesar $10 \%$ dari berat basah tanah gambut (Ma'ruf, M.A., dkk 2016).

Hal yang belum perhitungkan pada penelitian tersebut yaitu masih belum dicoba untuk diaplikasikan pada perhitungan daya dukung pondasi dangkal untuk aplikasi pemakaian lahan di lapangan nantinya, dimana dimana pengaruh kadar air dari tanah gambut di sekitar luasan yang distabilisasi juga akan memberikan pengaruh. Karenanya diperlukan penelitian lanjutan dengan mengimitasi besar pondasi dangkal yang umum digunakan pada masyarakat sekitar lahan tersebut.

Terkait dengan adanya hal di atas, maka diperlukan penelitian lanjutan menggunakan metode pengujian sifat teknis yaitu dengan uji direct shear dan uji konsolidasi agar diperoleh nilai karakteristik tanah gambut sebelum dan sesudah distabilisasi. Parameter ini kemudian digunakan sebaga input data pada perhitungan kapasitas daya dukung pondasi dangkal dan nilai penurunan tanah. Diharapkan dari hasil penelitian kali ini dapat diperoleh besaran perubahan kapasitas daya dukung pondasi dangkal dan nilai penurunan tanah.

\section{METODOLOGI PENELITIAN}

Ada beberapa tahapan penelitian yang dilakukan dalam skala laboratorium.

1. Pengujian tanah gambut kondisi awal

2. Pengujian sifat teknis tanah gambut sebelum dan setelah distabilisasi

3. Menentukan nilai kohesi, sudut geser dalam, dan besaran konsolidasi semua kondisi

4. Menghitung besar penurunan konsolidasi yang terjadi

5. Menghitung nilai daya dukung tanah untuk semua kondisi dengan model pondasi dangkal ukuran 1 x1 m.

6. Analisa dan kesimpulan

\section{Hasil Penelitian Dan Pembahasan \\ Pengujian Tanah Gambut Kondisi Awal Penelitian Kadar Organik dan Kadar Abu}

Tabel 1. Perhitungan kadar abu dan organik

\begin{tabular}{|l|c|c|c|c|c|}
\hline No. Container & & 1 & 2 & 3 & $\bar{X}$ \\
\hline 1. Wcont + Wsoil (dioven 24 jam) & gr & 45.9 & 62.3 & 62.7 & 57.0 \\
\hline 2. Wcont + Wsoil (difurnace $800^{\circ}$ ) abu & gr & 43.6 & 60.2 & 60.5 & 54.8 \\
\hline 3. Wcont + Wsoil (difurnace $800^{\circ}$ ) organik & gr & 44.1 & 60.7 & 61.1 & 55.3 \\
\hline 4. Wcont & gr & 43.4 & 60.0 & 60.4 & 54.6 \\
\hline 5. Kadar Abu $\left(A_{c}\right.$ ) & $\%$ & 20 & 20 & 10 & 16.7 \\
\hline 6. Kadar Organik $\left(\mathrm{O}_{c}\right)$ & $\%$ & 30 & 30 & 30 & 30 \\
\hline
\end{tabular}

Sumber: Data Sekunder

Dari tabel diatas diketahui bahwa tanah tersebut merupakan tanah gambut, karena kandungan bahan organik $\left(\mathrm{O}_{\mathrm{c}}\right)$ dan kandungan abu $\left(\mathrm{A}_{\mathrm{c}}\right)$ sampel memenuhi persyaratan USSR ( Mankinen dan Gelfer 1982) seperti yang terlihat pada tabel 2 . 
Tabel 2. Sistem klasifikasi tanah gambut dan tanah organik

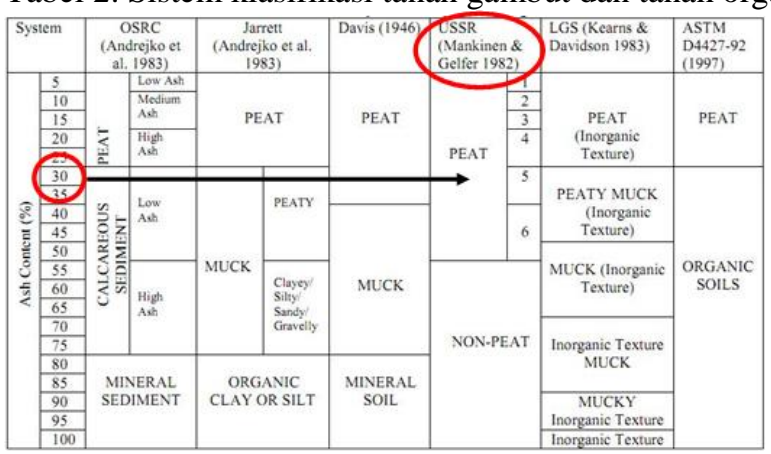

Sumber: E.C. Leong \& C.Y. Chin (1999)

Pengujian sifat teknis tanah gambut sebelum dan setelah distabilisasi

Tabel 3. Sifat teknis tanah gambut sebelum distabilisasi

\begin{tabular}{|c|l|c|c|}
\hline No. & Parameter & Satuan & Hasil uji \\
\hline 1. & Kuat geser & $\mathrm{kg} / \mathrm{cm}^{2}$ & 0,086 \\
\hline 2. & Konsolidasi & $\mathrm{Mm}$ & 4,74 \\
\hline
\end{tabular}

Sumber: Data Primer

Tabel 4. Sifat teknis tanah gambut setelah distabilisasi

\begin{tabular}{|c|l|c|c|c|c|c|}
\hline No. & Parameter & Satuan & inisial & $5 \%$ & $10 \%$ & $15 \%$ \\
\hline 1. & Kuat geser & $\mathrm{kg} / \mathrm{cm}^{2}$ & 0,073 & 0,098 & 0,300 & 0,280 \\
\hline 2. & Konsolidasi & $\mathrm{mm}$ & 4,74 & 3,95 & 1,49 & 2,19 \\
\hline
\end{tabular}

Sumber: Data Primer

\section{Kuat Geser}

Parameter kuat geser tanah gambut terkait erat dengan kondisi serat gambut dan parameter berat volume tanah. Hal ini dikarenakan tanah gambut termasuk dalam frictional material / non kohesive material (Adams, 1965) dimana kuat gesernya tergantung dari lekatan antar butiran padat (serat) tanah gambut. Dari hasil pengujian dapat dilihat bahwa nilai kuat geser masing-masing sampel berbeda, hal ini dikarenakan variasi persentase bahan stabilisasi yang digunakan. Untuk hasil nilai kuat geser yang paling optimum terjadi pada sampel tanah gambut yang dicampur dengan $10 \%$ bahan stabilisasi. Hal ini tentu berbanding lurus dengan hasil yang diperoleh pada saat pengujian berat volume. Dimana pada pengujian berat volume campuran $10 \%$ bahan stabilisasi adalah yang paling optimum. Hal ini terjadi karena jumlah persentase yang tepat untuk meningkatkan kemampuan tanah dalam menahan gaya horizontal. Pada persentase $10 \%$ kemungkinan terjadi reaksi sementasi yang optimum. Pada reaksi tersebut bahan stabilisasi mengikat serat tanah gambut dan membungkusnya. Sehingga mampu menambah kekuatan tanah dalam menahan gaya horizontal.

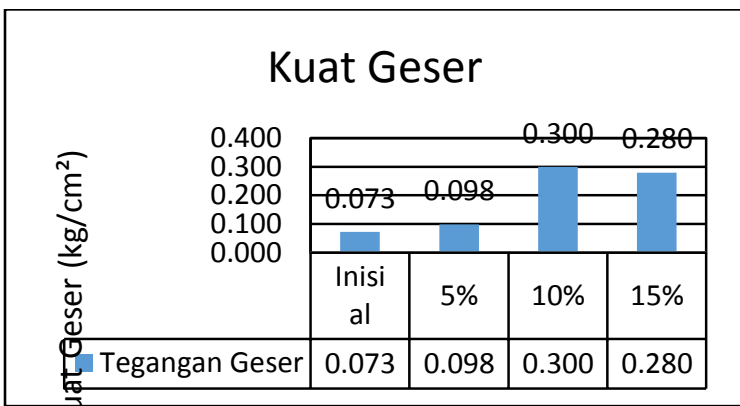

Gambar 1. Grafik kuat geser vs persentase bahan stabilisasi

Sumber: Data Primer

\section{Konsolidasi}

Dari hasil pengujian konsolidasi didapat angka penurunan yang terjadi bervariasi seiring dengan variasi persentase bahan stabilisasi yang digunakan. Hal ini tentu akan mempengaruhi kemampuan tanah untuk menahan gaya vertikal, sehingga terjadi variasi pemampatan. Berdasarkan hasil dari pengujian diperoleh bahwa pada sampel tanah gambut yang dicampur dengan $10 \%$ bahan stabilisasi merupakan yang paling optimum. Tetapi hasil ini tidak sesuai dengan pengujian yang lainnya dimana pada pengujian Gs dan kadar air campuran $15 \%$ yang paling optimum. Sedangkan pada pengujian berat volume dan angka pori campuran 5\% yang paling optimum. Dalam pengujian sifat fisik mungkin campuran 5\% dan $15 \%$ yang paling optimum, tetapi pada konsolidasi dapat diketahui bahwa kadar persentase campuran bahan stabilisasi $10 \%$ lebih tepat untuk dapat menjadi material penguat tanah untuk menahan gaya vertikal. Pada persentase $10 \%$ kemungkinan terjadi reaksi yang optimum antara bahan stabilisasi dan sampel tanah gambut. Reaksi yang mungkin terjadi, yaitu sementasi dimana bahan stabilisasi mengikat serat tanah gambut dan membungkusnya. Sehingga rongga-rongga yang terdapat pada sampel tanah berkurang. Hal ini dapat dibuktikan dengan nilai penurunan konsolidasi yang lebih kecil daripada yang lain.

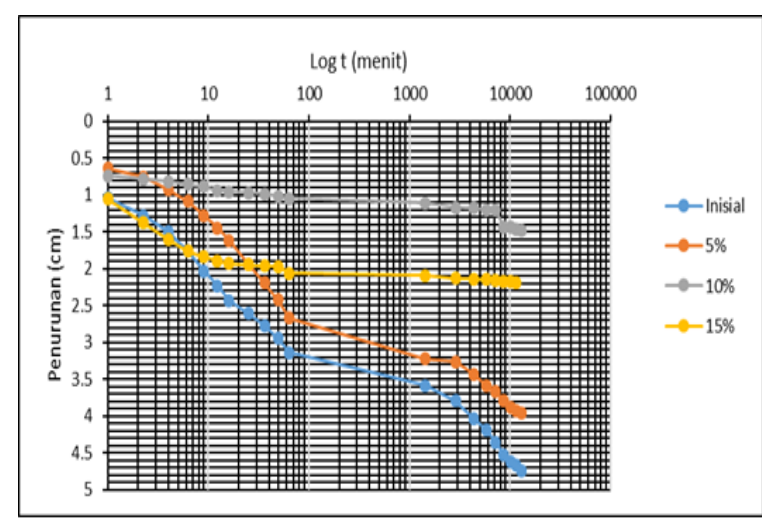

Gambar 2. Grafik penurunan dengan variasi persentasebahan stabilisasi vs log t pada uji konsolidasi Sumber: Data Primer

Dari hasil pengujian sifat teknis tanah yaitu campuran $10 \%$. Pada kuat geser terjadi peningkatan dimana awalnya sebesar $0,073 \mathrm{~kg} / \mathrm{cm}^{2}$ menjadi $0,300 \mathrm{~kg} / \mathrm{cm}^{2}$ dan terjadinya penurunan konsolidasi sebesar $68,57 \%$ dari tanah gambut 
inisial. Hal ini dapat terjadi dikarenakan pada persentase bahan campuran $10 \%$ tersebut sebagian besar materialnya mampu bereaksi dengan sampel tanah gambut sehingga terjadi proses sementasi yang menyebabkan peningkatan kekuatan tanah dalam menahan gaya vertikal dan horizontal yang terjadi. Proses sementasi yaitu suatu proses dimana perekatan oleh material lain, dimana pada penelitian ini kemungkinan serat-serat tanah gambut direkatkan oleh material fly ash yang terdapat dalam bahan stabilisasi.

Air gambut yang digunakan pada penelitian ini memiliki $\mathrm{pH}$ 1-2 (Asam). Berdasarkan penelitian sebelumnya yang telah dilakukan oleh Roitoman Sihombing, 2012 bahwa pH air gambut akan mengalami peningkatan. Hal ini disebabkan karena penambahan kapur tohor. Pada penelitian ini salah satu bahan stabilisasi yang digunakan yaitu kapur tohor. Jadi, pada saat melakukan permodelan seperti di lapangan air gambut yang awalnya memiliki $\mathrm{pH}$ asam ada kemungkinan $\mathrm{pH}$ airnya mengalami peningkatan karena pada campuran terdapat kapur tohor. Sehingga air tersebut ada kemungkinan malah membantu proses sementasi yang terjadi.

\section{Pengaplikasian Data Hasil Penelitian}

Dari data yang diperoleh pada pengujian di Laboratorium Mekanika Tanah Fakultas Teknik, Universitas Lambung Mangkurat dapat kita aplikasikan dalam perhitungan-perhitungan untuk mengetahui dampak dari proses stabilisasi tanah gambut. Pada perhitungan ini kita akan membandingkan hasil dari campuran tanah gambut dan $10 \%$ bahan stabilisasi dengan tanah gambut inisial. Diambil 10\% karena dari segi sifat teknisnya lebih bagus daripada yang lainnya. Perhitungan yang akan dilakukan meliputi daya dukung tanah dan daya dukung tiang. Hal ini dilakukan untuk menganalisis kemampuan tanah sebelum dilaksanakan pembangunan di atas tanah gambut tersebut.

\section{Daya Dukung Tanah}

Terzaghi.

Untuk perhitungan daya dukung digunakan rumus

$$
\mathrm{qu}=\mathrm{C} \cdot \mathrm{Nc}+\mathrm{q} \cdot \mathrm{Nq}+\frac{1}{2} \cdot \mathrm{B} \cdot \gamma \mathrm{t} \cdot \mathrm{N} \gamma
$$

Dimana:

$$
\begin{aligned}
& \mathrm{qu} \quad=\text { daya dukung ultimate }(\mathrm{kPa}) \\
& \mathrm{C}=\operatorname{kohesi}(\mathrm{kPa}) \\
& \mathrm{D}=\text { kedalaman }(\mathrm{m}) \\
& \gamma \mathrm{t} \quad=\text { berat volume tanah }\left(\mathrm{kN} / \mathrm{m}^{3}\right) \\
& \mathrm{B}=\text { lebar pondasi (m) } \\
& \mathrm{Nc}, \mathrm{Nq}, \mathrm{N} \gamma \quad \text { = faktor daya dukung } \\
& \text { (berdasarkan nilai sudut geser dalam) }
\end{aligned}
$$

Tabel 5. Data perhitungan daya dukung tanah

\begin{tabular}{cccc}
\hline Parameter & $\begin{array}{c}\text { Tanah } \\
\text { gambut inisial }\end{array}$ & $\begin{array}{c}\text { Tanah gambut } \\
\text { distabilisasi }\end{array}$ & Satuan \\
\hline Kohesi (C) & 0,018 & 0,064 & - \\
\hline $\begin{array}{c}\text { Berat volume } \\
\text { tanah }(\gamma \mathrm{t})\end{array}$ & 10,29 & 12,06 & $\mathrm{kN} / \mathrm{m}^{3}$ \\
\hline $\begin{array}{c}\text { Lebar pondasi } \\
(B)\end{array}$ & 1 & 1 & $\mathrm{~m}$ \\
\hline Kedalaman (D) & 1 & 1 & $\mathrm{~m}$ \\
\hline
\end{tabular}

\begin{tabular}{cccc}
\hline $\begin{array}{c}\text { Sudut geser } \\
\text { dalam }(\Phi)\end{array}$ & 14,0848 & 31,9765 & $\circ$ \\
\hline $\mathrm{Nc}$ & 12,9 & 52,6 & - \\
\hline $\mathrm{Nq}$ & 4,4 & 36,5 & - \\
\hline $\mathrm{N} \gamma$ & 2,5 & 35 & - \\
\hline
\end{tabular}

Sumber: Data Primer

a. Daya dukung tanah gambut inisial

$$
\begin{aligned}
\mathrm{qu}= & \mathrm{C} \cdot \mathrm{Nc}+\gamma \mathrm{t} \cdot \mathrm{D} \cdot \mathrm{Nq}+\frac{1}{2} \cdot \mathrm{B} \cdot \gamma \mathrm{t} \cdot \mathrm{N} \gamma \\
= & (0.018 \times 12,9)+(10,29 \times 1 \times 4,4)+\left(\frac{1}{2}\right. \\
& \times 1 \times 10,29 \times 2,5) \\
= & 58,371 \mathrm{kPa}
\end{aligned}
$$

b. Daya dukung tanah gambut yang telah distabilisasi dengan bahan stabilisasi $10 \%$

$$
\begin{aligned}
\mathrm{qu} \quad= & \mathrm{C} \cdot \mathrm{Nc}+\gamma \mathrm{t} \cdot \mathrm{D} \cdot \mathrm{Nq}+\frac{1}{2} \cdot \mathrm{B} \cdot \gamma \mathrm{t} \cdot \mathrm{N} \gamma \\
= & (0,064 \times 52,6)+(12,06 \times 1 \times 36,5)+\left(\frac{1}{2}\right. \\
& \times 1 \times 12,06 \times 35) \\
= & 654,606 \mathrm{kPa} \\
\mathrm{qu}(\text { inisial })<\mathrm{qu}(\text { stabilisasi }) & 58,371 \mathrm{kPa}<654,606 \mathrm{kPa}
\end{aligned}
$$

Berdasarkan hasil perhitungan di atas dapat disimpulkan bahwa nilai daya dukung tanah naik setelah proses stabilisasi. Hal ini dibuktikan dengan nilai qu stabilisasi lebih besar daripada qu inisial.

\section{KESIMPULAN DAN SARAN}

\section{Kesimpulan}

1. Pada pengujian sifat teknis, didapat bahwa persentase bahan stabilisasi $10 \%$ yang paling baik. Hal ini dapat dibuktikan dengan data-data hasil perhitungan. Untuk kuat geser $(\tau)$ terjadi peningkatan sebesar $310,94 \%$. Dimana pada saat setelah dicampur dengan bahan stabilisasi nilai kuat gesernya diperoleh sebesar 0,300 $\mathrm{kg} / \mathrm{cm}^{2}$ sementara nilai kuat geser tanah gambut inisial sebesar $0,073 \mathrm{~kg} / \mathrm{cm}^{2}$. Sedangkan pada saat pengujian konsolidasi terjadi penurunan nilai kemampumampatannya sebesar $68,57 \%$. Dimana pada saat setelah dicampur dengan bahan stabilisasi nilai kemampumampatannya sebesar $1,49 \mathrm{~mm}$ sementara nilai kemampumampatan tanah gambut inisial sebesar $4,74 \mathrm{~mm}$.

2. Untuk nilai daya dukung setelah dicampur dengan bahan stabilisasi terjadi peningkatan. Untuk tanah tanah gambut inisial daya dukungnya sebesar 58,371 $\mathrm{kPa}$, sedangkan setelah dicampur dengan bahan stabilisasi daya dukungnya meningkat menjadi 654,606 $\mathrm{kPa}$.

3. Pada saat pencampuran tanah gambut dengan bahan stabilisasi terjadi proses sementasi yang dibantu juga 
oleh adanya air gambut yang kemungkinan mengalami kenaikan $\mathrm{pH}$ diakibatkan adanya bahan kapur tohor pada campuran. Sehingga menyebabkan peningkatan kekuatan tanah.

\section{Saran}

Dalam melakukan penelitian tentang stabilisasi tanah gambut dengan menggunakan bahan stabilisasi berupa kapur dan fly ash, maka ada beberapa saran yang dapat kami berikan antara lain sebagai berikut:

1. Perlu dilakukan penelitian pada kapur dan fly ash untuk mengetahui reaksi yang terjadi serta pengaruhnya terhadap unsur-unsur penyusun tanah gambut.

2. Perlu adanya penelitian lebih lanjut tentang kandungan kimia yang terdapat pada air gambut.

\section{Ucapan Terima Kasih}

Ucapan terima kasih kami berikan kepada Program Studi Teknik Sipil Universitas Lambung Mangkurat yang telah mendanai penelitian ini, serta kepada saudara Adhitya Dwiki Darma Putra (H1A111053) yang telah membantu terlaksananya penelitian ini.

\section{DAFTAR PUSTAKA}

Adams, J.I. (1961). "Laboratory Compression Tests on Peat". Proc. Seventh Muskeg Res. Conf., NRC, ACSSM Tech. Memo. 71, pp.36-54.

Adams, J.I. (1965). "The Engineering Behaviour of a canadian Muskeg". Proc.Sixth International Conference On Soil Mechanics and Foundation Engineering. Vol.1, pp 3-7.

Akroyd, T.N.W. (1957). "Laboratory Testing in Soil Engineering”. Soil Mechanics Limited, London, 233pp.

Anderson, K.O. and R.A. Hemstock (1959). "Relating Some Engineering Properties of Muskeg to Some Problems of Field Construction". Proc. Fifth Muskeg Res.Conf.,NRC, ACSSM Tech. Memo. 61, pp.16-25.

Andriesse, J.P. (1994). "Constrainsts and opportunities for alternative use options of tropical peat land". In B.Y, Aminuddin (Ed.). Tropical Peat; Proceedings of International Symposium on Tropical Peatland, Kuching, Sarawak, Malaysia.

ASTM Annual Book (1992). "Standard Classification of Peat Samples by Laboratory Testing (D442792)". ASTM, Section 4, Volume 04.08 Soil and Rock, Philadelphia.

Bain v Bowles. (1991). IRLR 356 (CA).

BB Litbang SDLP (Balai Besar Penelitian dan Pengembangan Sumberdaya Lahan Pertanian) (2008). "Laporan Tahunan 2008, Konsorsium Penelitian dan Pengembangan Perubahan Iklim pada Sektor Pertanian". Balai Besar Penelitian dan Pengembangan Sumberdaya Lahan Pertanian Bogor.
Boelter, D.H. (1968), “Important Physical Properties of Peat Materials". Proc. Of The Third International Peat Congress, Quebec, Canada.

Brooks, R.M. (2009). Soil stabilization with fly ash and rice husk ash. International Journal of Research and Reviews in Applied Sciences, 1(3), PP.209-2017.

Colley, B.E. (1950). "Construction of Highways Over Peat and Muck Areas". Am. Highways, Vol. 29, No. 1.

Cook, P.M. (1956). "Consolidation Characteristics of Organic Soils". Proc., Ninth Can. Soil Mech. Conf., NRC. ACSSM Tech. Memo. 41. Pp 82-87.

Departemen Pekerjaan Umum, (2005). "Stabilisasi dangkal tanah lunak untuk konstruksi timbunan jalan (dengan semen dan cerucuk)". Pusat Litbang Prasana Transportasi: Jakarta.

Dhowian, A,W and T.B. Edil (1980). " Consolidation Behaviour of Peat". Geatechnical Testing Journal, Vol.3. No. 3. pp 105-144.

Duraisamy. Y., Huat. Bujang. B. K., Aziz. Azlan A., (2007). "Compressibility Behavior of Tropical Peat Soil Reinforced with Cement Column" American journal of Applied Sciences 4 (10): 786-791, ISSN 1546-9239.

Edil, T. \& Dhowian, A.W.(1981). "At-Rest Lateral Pressure of Peat Soils". ASCE, vol.107: 201-217.

Handayani, I.P. (2003). "Studi Pemanfaatan Gambut Asal Sumatra". Lokakarya Pengelolaan Lahan Gambut Berkelanjutan-Wetlands International- Indonesia Programe.

Hanrahan, E.T. (1954). "An Investigation of Some Physical Properties of Peat". Geotechnique, Vol.4, No 3.

Hanrahan, E.T. (1964). " A Road Failure on Peat". Geotechnique-September.

Hasyim, R, S., Islam (2008). "Engineering Properties of Peat Soil in Peninsular, Malaysia. journal of Applied Sciences ISSN 1812-5654.

Hellis, C.F. and C.O. Brawner (1961). "The Compressibility of Peat with Reference to Major Highway Construction in British Columbia. Proc. Seventh Muskeg Res. Conf, NRC. ACSSM. Tech, Memo 71, pp 204-227.

Hendry (1998). "Perbaikan Tanah Gambut Pulau Padang Dengan Campuran Semen-Renolith Dalam Kaitannya Sebagai Lapisan Dasar Konstruksi Jalan". Master Thesis JBPTITBPP/2007-03-06. ITB Central Library.

Huat, Bujang B.K. (2004) dalam Yulindasari (2006). Malaysia

Jamil, dkk (1989). Indonesia.

Kearns, F.L., Autin, W.J., and Gerdes, R.G. (1982). "Geological Society of American Abstracts with Programs". N.E. and S.E Sections, Vol. 14, No.1 and 2.

Luttig (1986). "Aspects of Water Retention and Dewatering in Peat". Charles H. Fuchsman (Publishers) London and New York.

Landva, A.O. and La Rochelle, P. (1982). "Compressibility and shear characteristics of 
Radforth peat. ASTM STP 820". Testing of Peats and Organic Soil, P. Jarret, ed.

Mankinen, G.W. and Gelfer, B. (1982). "Compressive Use Peat in The USSR". DOE 5th Technical Conference of Peat.

MacFarlane, I.C. (1959). "Muskeg Engineering Handbook". National Research Council of Canada, University of Toronto Press, Toronto, Canada. MacFarlane, I.C. dan Radforth, N.W. (1965). "A Study of Physical Behaviour of Peat Derivatives Under Compression. Proceeding of The Tenth Muskeg Research Conference. National Research Council of Canada, Technical Memorandun No 85.

Mochtar, Noor E. (1985). "Compression of peat soils." $\mathrm{Ph} . \mathrm{D}$. Thesis Univ. of Wisconsin-Madison, USA.

Mochtar, Noor E. dan Mochtar, Indrasurya B. (1991). "Studi Tentang Sifat Phisik dan Sifat Teknis Tanah Gambut Banjarmasin dan Palangkaraya Serta Alternatif Cara Penanganannya untuk Konstruksi Jalan". Dipublikasi sebagai hasil penelitian BBI dengan dana dari DIKTI Jakarta.

Mochtar, N.E. et al. (1999), "Aplikasi Model Gibson \& Lo untuk Tanah Gambut Berserat di Indonesia", Jurnal Teknik Sipil, ITB, Vol. 6 N0. 1.

Pasaribu, A.S. (1998)."Konstruksi Jalan di Tanah Gambut”. Prosiding Seminar Nasional Gambut III. Pontianak, Kalimantan Barat.

Skempton, A, W (1970), "The Consolidation of clays by Gravitational Compaction", Quarterley Journal of Engineering Geology, 373-411.

Van De Meene (1984), "Geological Aspects of Peat Formation in The Indonesian- Malyasin Lowlands", Bulletin Geological Research and Development Centre, 9, 20-31.

Von Post, L. (1992). "Sveriges Geologiska Undersoknings Torvinventering Och Nagre av Dess Hittills Vunna Resultat". Sv. Mosskulturfor. Tidskr. 1:1-27. 